\title{
ASSESSMENT OF CHANGES IN SOMATIC CHARACTERISTICS BASED ON THE LEVEL OF PHYSICAL ACTIVITY IN WOMEN WHO UNDERTOOK WEIGHT REDUCTION COURSE
}

\author{
Tereza Sofková1, Miroslava Přidalová2 \\ 'Department of Anthropology and Health Education, Faculty of Education, Palacký University Olomouc, Olomouc, Czech Republic \\ ${ }^{2}$ Department of Natural Sciences in Kinanthropology, Faculty of Physical Culture, Palacký University Olomouc, Olomouc, Czech Republic
}

\begin{abstract}
SUMMARY
Objective: Obesity is a chronic disease in modern age and finding approach to the prevention, diagnosis and treatment of obesity has its place among the priorities of modern medicine and related fields. Important component in programmes to reduce overweight and obesity is regular physical activity (PA), which plays vital role in the comprehensive approach to the treatment of obesity. Primary objective of our study was to assess changes in somatic characteristics following eleven weeks of PA in overweight and obese women aged 30 to 60 years.

Methods: Our research sample consisted of 221 women who were classified according to the level of PA carried out, namely $1^{\text {st }}, 2^{\text {nd }}$ and $3^{\text {rd }}$ category. STOB (STop OBesity) course participants underwent PA monitoring and diagnosis of the body composition, which is a modern multifaceted cognitive behavioural method.

Results: Younger highly active women (PA 3) achieved higher average differences in body fat than did women with the typical daily activity (PA 1), however, significant differences have not been found. Statistically significant differences in visceral fat between the 1 15t (PA 1) and $3^{\text {rd }}$ PA category (PA 3) have been observed in older women.

Conclusion: Given the significantly higher increase of fat-free mass percentage in older highly active women (PA3), we may assess the course results positively. Our study demonstrated positive correlation between carrying out the recommended level of PA and its impact on the body composition's health risk indicators. Obese women should walk at least 10,000 steps per day to improve their health.
\end{abstract}

Key words: body composition, overweight and obesity, pedometer, walking

Address for correspondence: T. Sofková, Department of Anthropology and Health Education, Faculty of Education, Palacký University Olomouc, Žižkovo nám. 5, 77140 Olomouc, Czech Republic. E-mail: tereza.sofkova@upol.cz

https://doi.org/10.21101/cejph.a4678

\section{INTRODUCTION}

Accelerated pace of life, consumerism, hypokinesia and excessive energy intake are causing high prevalence of overweight and obesity. Obesity is called pandemic of the 21st century; from the perspective of somatic diagnosis overweight and obesity characterises excessive weight, high proportion of fat component, and regression of muscle fractions (1).

We consider the body composition as the acceptable indicator of the functional state of the body and its fitness. Different body components, particularly body fat, lean mass and visceral fat are appropriate indicators of somatic condition. Long-term reduction in physical activity (PA) is reflected in the inadequate representation of the different body fractions and body composition's health risk indicators (2-4).

The body composition may be analysed in many ways, as there are a number of methods differing in their accuracy of results, cost, feasibility in the field or laboratory conditions and difficulty for the measured person as well as for those carrying out the measurement. Multi-frequency bioelectrical impedance method is based on the differences in propagation of alternating electric current of varying intensity and in different biological structures. This method is commonly used in the world's top establishments $(5,6)$.

PA is one of the most significant components of health and healthy lifestyle. Regular PA prevents obesity and is a natural tool for its reduction as it has a long-term impact on retaining reduced weight. It prevents reduction in resting metabolic rate and lean body mass. The regular PA promotes health and prevents number of diseases, as well as improves the social connectivity and quality of life (7).

Every year the number of people who are at risk of overweight and obesity is increasing, consequently, it is essential to find natural way for people to carry out key recommendations relating to the different types of PA. Suitable PA, which is available for everyone regardless of age and sex is walking, which may be monitored by pedometers. Essentially, the habitual PA comprises all daily activities hence this form of monitoring enables the public to acquire key information about its level (8). As the daily universal standard, it is recommended to walk at least 10,000 steps to promote health (9-11).

An integral part of the weight reduction course is change in attitude to nutrition and physical stereotypes. Cognitive behav- 
ioural therapy, among others in the STOB (STop OBesity) weight reduction courses, promotes by means of coaching new approach to the nutrition and movement stereotypes. Survey carried out by the STOB found that $40 \%$ of one thousand course participants maintain 5\% reduction in the course admission weight after the gap of 2 to 7 years from the end of the course (12). For that reason, the primary objective of our research was to assess the changes in selected body composition fractions in relation to eleven weeks of PA in overweight and obese women aged 30 to 60 years.

\section{MATERIALS AND METHODS}

\section{Participants}

The research sample consisted of 221 middle aged (between 30 and 60 years of age) obese and overweight women from Olomouc and its environs who regularly attended the STOB weight reduction courses. Monitored groups Maturus I $(n=118 ; 38.4 \pm 6.7$ years $)$ and Maturus II $(\mathrm{n}=103 ; 52.1 \pm 5.3$ years $)$ were further divided into subgroups using the K-means clustering method. Subgroups were categorised in accordance with the Tudor-Locke and Bassett classification (10), namely relating to the number of steps walked per day during the course and counted with the aid of pedometer (PA 1 - typical daily activity; PA 2 - active women; PA 3 - highly active women).

Diagnosing medical condition at the beginning and end of the course as well as the monitoring of PA was outside the course programme. Each woman signed written agreement with measurements to be carried out and was familiarised with the research conditions. Furthermore, the participants were familiarised with the rules, compliance of which was essential to acquire valid information relating to the body composition, use of pedometer and keeping records in the log sheet. Women were always familiarised with the results of the entry and exit examination.

\section{Assessment of Body Composition}

Standardised anthropometric methods for determining the key somatic parameters, namely the body height and body weight were used. The body height was measured with the accuracy of $0.5 \mathrm{~cm}$ using P-226 anthropometer manufactured by Trystom, Czech Republic. The body mass was measured using the below described InBody 720 device. Body Mass Index (BMI) was used to assess overweight and obesity (overweight: 25.00 to $29.99 \mathrm{~kg}$ / $\mathrm{m}^{2}$, obesity: $\left.\geq 30.00 \mathrm{~kg} / \mathrm{m}^{2}\right)(13,14)$.

The InBody 720 device, using directly controlled bioelectric impedance method ( 1 to $1,000 \mathrm{kHz}$ ), was used for the diagnosis of body composition. The principle of bioelectrical impedance method is based on differences in the propagation of high frequency alternating electrical current of varying intensity in different biological structures. It is non-invasive and time saving method. The device differentiates body weight into three components - total body water, dry matter (proteins and minerals) and body fat. The InBody 720 is also able to analyse the quantity of visceral fat, which is defined as transversal cross-sectional area in the abdominal area at the L4-L5 level. Correlation between the computed tomography (CT) and InBody 720 methods is defined at $r=0.92$ level (15).

\section{Monitoring of Physical Activity}

PA was monitored during the eleven weeks long course with the aid of the Digi Walker Yamax SW-701 pedometer and the $\log$ sheet where participants recorded the number of steps at the start and finish of PA. Pedometer is an electronic device measuring vertical oscillations with the aggregate daily number of steps showed on display. Generally, pedometers are the most accurate in counting the number of steps and are recommended to monitor PA (16-18).

\section{Weight Reduction Course}

The theoretical syllabus of eleven weeks course aimed to change the day-to-day living habits, nutritional stereotypes included physical therapy (cognitive behavioural psychotherapy). This psychological method of treatment is based on the assumption that inappropriate eating and exercise habits are learned and thus may be weaned out. Application of the psychotherapy and relaxation techniques enables obese individuals to overcome negative emotions, stress, depression, and anxiety. The methodology is applied to a group, as members of the group are mutually supportive. Weight reduction diet was the basis of nutritional intervention and corresponded to the caloric value of $4,800 \mathrm{KJ}$ $(1,150 \mathrm{kcal})$ per day at the rate of five meals a day (12).

Theory included 60 minutes per week cognitive behavioural therapy with the analysis of the diet and PA of the previous week. The PA records using the Yamax pedometer enabled to monitor whether the objective of carrying out 10,000 steps per day was met. The practical part included exercises (60-minute unit), which consisted of the initial phase, namely warming up, stretching, aerobic fitness (40 to 45 minutes) and compensatory part, i.e. stretching (15 minutes), relaxation and anti-stress exercises.

\section{Statistical Analysis}

In order to analyse the relationship between body composition and PA level the group was divided into 3 sub-groups using the K-means clustering method: women with typical daily activity (PA 1), active women (PA 2) and highly active women (PA 3) (10). Descriptive statistics and analysis of data were processed using the Statistica 10.0 statistical program. Using the two-factor Analysis of Variance, we tested the significance of changing individual parameters in relation to age and PA level. We selected the Scheffe Test as the post-hoc test of the Analysis of Variance to monitor differences between respective pairs. Statistical significance was set at $\mathrm{p}<0.05$.

\section{RESULTS}

The characteristics of eleven weeks PA relating to different categories are shown in Table 1. Women were divided in accordance with the Tudor-Locke and Bassett (10) classification and the level of PA carried out during the course to women with typical daily activity (PA 1), active women (PA 2) and highly active women (PA 3).

Entry values for different groups differentiated by age (Maturus I - MI; Maturus II - M II) are shown in Table 2 and 3. The BMI values are in the obese category, i.e. BMI $\geq 30 \mathrm{~kg} / \mathrm{m}^{2}$. The 
percentage of total body water (TBW, litres) did not exceed the $50 \%$ limit in any group, which corresponds with the assumption that the quantity of TBW is in reciprocal relationship to the body fat mass (BFM, kg). The percentage of TBW in younger women was 38.1 litres (MI: $42.5 \%$ of the total weight), in older women it reached even lower average value of 36.1 litres (MII: 41.6\% of total body weight). We observed that the body composition's health indicators risk limits were significantly exceeded in all subgroups. The BFM was very high, during the entry examination it exceeded $35 \mathrm{~kg}$ and body fat percentage (BFP, \%) exceeded $40 \%$. In case of visceral fat $\left(\mathrm{VFA}, \mathrm{cm}^{2}\right)$, which far exceeded the recommended values of $>100 \mathrm{~cm}^{2}$, we recorded significantly higher VFA in older women (MI: $135.8 \mathrm{~cm}^{2}$; MII: $155.1 \mathrm{~cm}^{2}$ ).

Table 2 shows reduction in selected somatic characteristics among younger women following eleven weeks of PA. Younger women, i.e. PA 3 level, reached higher average differences in the BFP and BFM than women with PA 1, however, significant differences have not been found. No statistically significant differences were observed in selected somatic characteristics among PA categories in younger women.

Reduction in selected somatic characteristics in older women, related to the categories of PA, is presented in Table 3. Statistically

Table 1. Average number of steps per day carried out during the course $(N=221)$

\begin{tabular}{|l|c|c|c|c|}
\hline \multirow{2}{*}{} & \multicolumn{2}{|c|}{$\begin{array}{c}\text { Maturus I } \\
(\mathrm{n}=118)\end{array}$} & $\mathbf{2}$ & $\begin{array}{c}\text { Maturus II } \\
(\mathbf{n}=103)\end{array}$ \\
\cline { 2 - 5 } & $\mathrm{n}$ & $\mathbf{M} \pm$ SD & 36 & $\mathrm{M} \pm$ SD \\
\hline PA1 & 41 & $7,621 \pm 1,589$ & 47 & $6,615 \pm 1,815$ \\
\hline PA2 & 46 & $10,212 \pm 1,717$ & 20 & $10,500 \pm 1,890$ \\
\hline PA3 & 31 & $13,462 \pm 1,964$ & $15,096 \pm 2,782$ \\
\hline
\end{tabular}

PA 1 - women with typical daily activity, PA 2 - active women, PA 3 - highly active women; values are given as $\mathrm{M} \pm \mathrm{SD}$

Table 2. Assessment of differences in selected somatic characteristics in relation to the younger women's PA category

\begin{tabular}{|c|c|c|c|c|c|c|c|c|c|c|}
\hline & \multicolumn{9}{|c|}{ Maturus I } \\
\hline & & \multicolumn{2}{|c|}{$\begin{array}{c}\text { PA 1 } \\
(n=41)\end{array}$} & \multicolumn{2}{|c|}{$\begin{array}{c}\text { PA 2 } \\
(n=46)\end{array}$} & \multicolumn{2}{|c|}{$\begin{array}{c}\text { PA 3 } \\
(n=31)\end{array}$} & \multicolumn{3}{|c|}{ p_PA } \\
\hline & $M \pm S D$ & M & $S D$ & M & SD & M & SD & $1-2$ & $2-3$ & $1-3$ \\
\hline Weight (kg) & $89.5 \pm 16.4$ & -3.6 & 2.7 & -4.9 & 3.8 & -3.6 & 2.8 & 0.21 & 0.27 & 0.99 \\
\hline $\mathrm{BMI}\left(\mathrm{kg} / \mathrm{m}^{2}\right)$ & $32.3 \pm 5.5$ & -1.3 & 0.9 & -1.8 & 1.4 & -1.3 & 0.9 & 0.19 & 0.25 & 0.96 \\
\hline BFP $(\%)$ & $40.5 \pm 6.3$ & -1.7 & 1.9 & -2.3 & 1.6 & -2.6 & 1.9 & 0.40 & 0.65 & 0.23 \\
\hline BFM (kg) & $36.1 \pm 11.6$ & -2.9 & 2.4 & -4.3 & 2.9 & -3.3 & 2.2 & 0.10 & 0.30 & 0.66 \\
\hline VFA $\left(\mathrm{cm}^{2}\right)$ & $135.8 \pm 43.8$ & -11.8 & 11.6 & -13.5 & 11.3 & -10.5 & 7.7 & 0.61 & 0.41 & 0.73 \\
\hline FFP (\%) & $59.8 \pm 6.3$ & 1.7 & 1.9 & 2.3 & 1.6 & 2.6 & 1.9 & 0.40 & 0.62 & 0.22 \\
\hline FFM (kg) & $51.4 \pm 6.6$ & -0.7 & 0.7 & -0.5 & 1.5 & -0.3 & 0.9 & 0.73 & 0.55 & 0.38 \\
\hline TBW (I) & $38.1 \pm 4.8$ & -0.5 & 0.5 & -0.4 & 1.1 & -0.2 & 0.7 & 0.82 & 0.58 & 0.46 \\
\hline
\end{tabular}

PA 1 - women with typical daily activity, PA 2 - active women, PA 3 - highly active women, BMI - body mass index, BFP - body fat percentage, BFM - body fat mass, VFA - visceral fat, FFP - fat-free mass percentage, FFM - fat-free mass, TBW - total body water. Entry values are given as M \pm SD, $\mathrm{P} \_$PA - statistical significance of the difference between subgroups in relation to the level of PA $(p<0.05)$.

Table 3. Assessment of differences in selected somatic characteristics in relation to the older women's PA category

\begin{tabular}{|c|c|c|c|c|c|c|c|c|c|c|}
\hline & \multirow[b]{3}{*}{$\mathrm{M} \pm \mathrm{SD}$} & \multicolumn{9}{|c|}{ Maturus II } \\
\hline & & \multicolumn{2}{|c|}{$\begin{array}{c}\text { PA 1 } \\
(n=36)\end{array}$} & \multicolumn{2}{|c|}{$\begin{array}{c}\text { PA 2 } \\
(n=47)\end{array}$} & \multicolumn{2}{|c|}{$\begin{array}{c}\text { PA 3 } \\
(n=20)\end{array}$} & \multicolumn{3}{|c|}{ p_PA } \\
\hline & & M & SD & M & SD & M & $S D$ & $1-2$ & $2-3$ & $1-3$ \\
\hline Weight (kg) & $86.6 \pm 13.1$ & -3.3 & 2.7 & -4.4 & 2.6 & -6.7 & 2.4 & 0.20 & 0.05 & 0.005 \\
\hline $\mathrm{BMI}\left(\mathrm{kg} / \mathrm{m}^{2}\right)$ & $32.2 \pm 4.5$ & -1.2 & 1.1 & -1.6 & 0.9 & -2.7 & 1.1 & 0.20 & 0.04 & 0.005 \\
\hline BFP $(\%)$ & $42.1 \pm 5.6$ & -1.7 & 1.7 & -3.1 & 1.8 & -4.3 & 2.1 & 0.03 & 0.07 & 0.001 \\
\hline BFM (kg) & $36.4 \pm 9.5$ & -3.1 & 2.5 & -4.1 & 2.3 & -6.2 & 2.4 & 0.15 & 0.04 & 0.003 \\
\hline $\operatorname{VFA}\left(\mathrm{cm}^{2}\right)$ & $155.1 \pm 33.6$ & -10.0 & 9.5 & -14.0 & 8.8 & -21.0 & 9.5 & 0.16 & 0.12 & 0.020 \\
\hline FFP (\%) & $57.8 \pm 5.6$ & 1.7 & 1.7 & 3.1 & 1.8 & 4.3 & 2.1 & 0.02 & 0.08 & 0.001 \\
\hline FFM (kg) & $49.1 \pm 5.8$ & -0.2 & 1.1 & -0.3 & 0.9 & -0.5 & 1.2 & 0.86 & 0.56 & 0.500 \\
\hline TBW (I) & $36.1 \pm 4.2$ & -0.1 & 0.8 & -0.2 & 0.7 & -0.4 & 0.9 & 0.78 & 0.59 & 0.470 \\
\hline
\end{tabular}

PA 1 - women with typical daily activity, PA 2 - active women, PA 3 - highly active women, BMI - body mass index, BFP - body fat percentage, BFM - body fat mass, VFA - visceral fat, FFP - fat-free mass percentage, FFM - fat-free mass, TBW - total body water. Entry values are given as $M \pm S D ; p$ difference between subgroups in relation to the level of PA $(p<0.05)$. 
significant differences in the body composition's health indicators associated with the abdominal obesity (VFA) between the PA's 1 st and 3rd categories were observed in elderly women. Given the significantly higher increase of the fat-free mass percentage (FFP) in older highly active women (PA 3), we may assess the course results as positive. Minimum FFP differences between the age categories were found for PA 1 level. Among the older women PA 1 and PA $2(p=0.020)$, PA 1 and PA $3(p=0.001)$ categories we found statistically significant differences when the FFP increased. Among younger and older women at PA 3 level $(p=0.020)$ we observed statistically significant differences when the FFP increased. Older women's PA 3 category (weight loss 6.7 $\mathrm{kg}$, BFP decrease $4.3 \%$, increase in FFP $4.3 \%$ ) appear to be the most successful when assessing the weight reduction.

Figure 1 shows reduction in the BFP in women with different levels of meeting the eleven weeks of PA objectives. Among the older women PA 1 and PA 2 ( $p=0.030)$, PA 1 and PA 3 ( $p=0.001)$ categories we found statistically significant differences in the BFP reductions. The average reduction and $95 \%$ confidence interval of the BFP reduction at PA 1 level are almost homogeneous for both age groups. We found statistically significant differences $(p=0.010)$ among younger and older women at PA 3 level.

\section{DISCUSSION}

Regular PA is a natural tool for reducing overweight and obesity and promotes long-term upkeep of reduced weight. Within the weight reduction programme (STOB course), PA is prescribed as part of the cognitive behavioural therapy. According to Fox (19), PA carried out within the group is means of helping to improve the psychological well-being, particularly in middle age women. Women have the opportunity to share their feelings, attitudes and problems with other women of similar age. The feeling of satisfaction is one of the basic prerequisites for successful exercise programme.

We may assume that at the beginning of the weight reduction regime women are sufficiently motivated by PA as means to reduce weight. After certain time span the amount and intensity of PA levels out during the weekly programme. Women encounter other obese individuals during the course and may lose psycho-

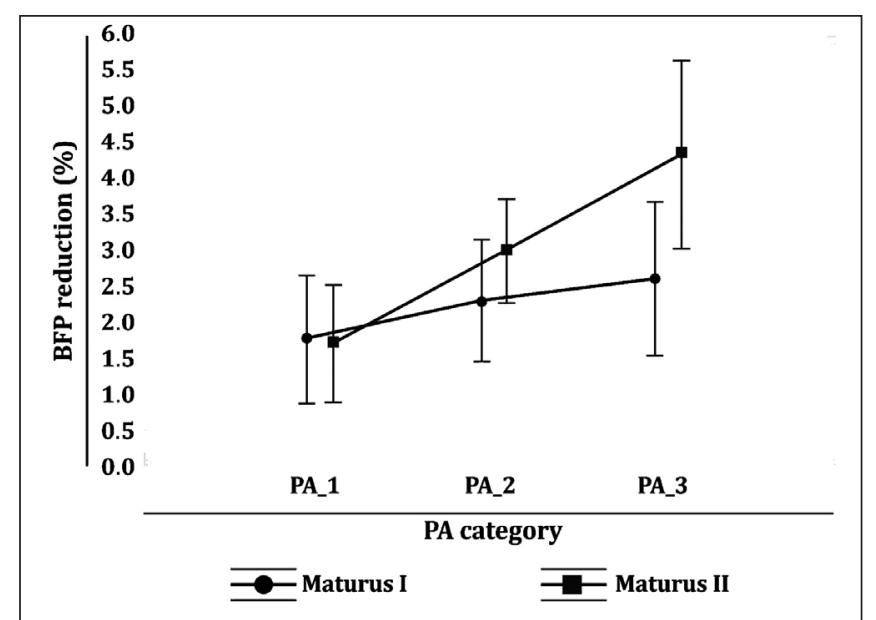

Fig. 1. Average reduction and $95 \%$ confidence interval of body fat percentage in monitored subgroups. logical barriers associated with obesity. Sometimes the association creates competition, which relates to the intrinsic motivation, however, the disadvantage is that it is not always possible to set the individual level of PA. In practice the initial physical condition, namely the lack of fitness, must be taken into account and consequently the level of PA should be gradually increased. However, the study by O'Meara et al. (20) shows that the most effective slimming programme includes continuous contact with a therapist or therapeutic group.

The impact of PA will mainly be felt in reduced fat fraction percentage while maintaining the amount of lean body mass (6, 21). Higher reduction of the fat fraction (BFM, BFP) is demonstrated in obese women who increased the PA level during the three-month intervention programme (22).

The physical activity increases the energy expenditure after exercise, it also increases the quiescent energy expenditure and energy expenditure associated with non-physical movement activities. Dynamic loading that increases the cardiorespiratory performance is the most suitable for reduction in weight, thereby improving transfer of oxygen to the muscles, which is a condition for using fat as the source of energy. Regular exercise activity will help to minimise muscle loss associated with the advancing age. Atrophy of myocytes with selective loss of fast type 2 fibers causes fragmentation and disappearance of the Z-lines and ligament enlargement, which results in less efficient dispersion of oxygen from capillaries. In addition, the number of motor units is reduced, the ratio of the number of capillaries to the fibers changes, the amount of mitochondria decreases, and the enzymatic activity per unit of muscle mass decreases. We believe that in the older group of women, physical activity had a significant positive effect on mitochondria, which have crucial effect on the body fitness and performance. Tudor-Locke and Bassett proposed the PA assessment based on the number of steps in healthy adults, for active individuals 10,000 steps per day and 12,500 steps per day for highly active individuals. To minimise impact of advancing age on the body composition we recommend that obese women over 30 years of age walk at least 10,000 steps per day and obese women over 45 years of age at least 12,500 steps per day (23-25).

King et al. (26), Ross and Janiszewski (27) and Annesi (28) showed that PA can bring health benefits without changes in anthropometric indicators and thus reduces the risk of complications of obesity, improves psychological well-being and also leads to better adherence to the reduction regime. The exercise alone does not always result in significant weight reduction, but has a number of positive effects relating to, inter alia, improvement of physical condition and thus positively affecting health. Improvement is also seen in the long-term observance of the reduction programme and is significantly reflected in the body composition $(2,6,22,29)$.

Monitoring daily number of steps using a pedometer does not include all the daily PA (e.g. swimming, cycling, etc.), however, it is a good orientation tool and motivator. Motivational effect of monitoring is reflected in the endeavour to carry out higher number of steps per day and in the context of competition between women. Using pedometer is regarded as a means of increasing the level of PA $(8,30,31)$ in all age groups and different interventions, although the greater effect is achieved in women (32). Sofková et al. (33) point out that more active environment, namely increasing number of steps, is positively reflected in a more optimal body composition. 
Conception of the STOB courses provides positive incentives for PA and thus we may assume that in women who do not attend the said weight reduction programmes the prevalence of sedentary lifestyles is higher. Educational effect presented in the STOB courses is important, as the significance of exercise is not always appreciated.

\section{CONCLUSION}

Our research results showed that meeting the recommendations relating to the number of steps per day is proving to be an effective means to reduce the risk of overweight and obesity, and particularly having positive influence on the body composition's health risk indicators. To minimise the gradual regression of muscle mass whilst the fat mass increases we recommend that obese women over 30 years of age walk at least 10,000 steps per day and obese women over 45 years of age at least 12,500 steps per day.

It was demonstrated that the higher level of PA during the eleven weeks programme results in reduction in selected somatic characteristics associated with the risk aspects of overweight and obesity. Highly active older women (PA 3) achieved higher statistically significant average differences in the waist parameters, body weight, BMI, body fat (BFM, BFP), and visceral fat (VFA) than women with typical daily activity (PA 1). Statistically significant differences were not observed in younger women.

\section{Conflict of Interests}

None declared

\section{REFERENCES}

1. Hoeger WWK, Hoeger SA. Fitness and wellness. 8th ed. Belmont, CA: Wadsworth Cengage Learning; 2009.

2. Hornbuckle LM, Bassett DR, Thompson DL. Pedometer-determined walking and body composition variables in African-American women. Med Sci Sports Exerc. 2005;37(6):1069-74.

3. Gába A, Přidalová M. Age-related changes in body composition in a sample of Czech women aged 18-89 years: a cross-sectional study. Eur J Nutr. 2014;53(1):167-76.

4. Thompson DL, Rakow J, Perdue SM. Relationship between accumulated walking and body composition in middle-aged women. Med Sci Sports Exerc. 2004;36(5):911-4.

5. Heyward VD, Wagner DR. Applied body composition assessment. 2nd ed. Champaign, IL: Human Kinetics; 2004.

6. Kyle UG, Morabia A, Schutz Y, Pichard C. Sedentarism affects body fat mass index and fat-free mass index in adults aged 18 to 98 years. Nutrition. 2004;20(3):255-60.

7. Anderson PM, Butcher KE. Childhood obesity: trends and potential causes. Future Child. 2006;16(1):19-45.

8. Sigmund E, Frömel K, Neuls F. Physical activity of youth: evaluation guidelines from the viewpoint of health support. Acta Universitatis Palackianae Olomucensis. Gymnica. 2005;35(2):59-68.

9. Roubenoff R. Sarcopenia and its implications for the elderly. Eur J Clin Nutr. 2000;54 Suppl 3:S40-7.

10. Tudor-Locke C, Bassett DR. How many steps/day are enough? Preliminary pedometer indices for public health. Sports Med. 2004;34(1):1-8.

11. U. S. Department of Health and Human Services. 2008 Physical activity guidelines for Americans [Internet]. U. S. Department of Health and
Human Services; 2008 [cited 2018 Aug 23]. Available from: http://www. health.gov/paguidelines/pdf/paguide.pdf.

12. Málková I. Reasonable, healthy and permanent loss of weight. Prague: Smart Press, s. r. o.; 2005. (In Czech.)

13. Riegerová J, Přidalová M, Ulbrichová M. Application of physical anthropology in physical education and sports. Olomouc: Hanex; 2006. (In Czech.)

14. World Health Organization. Global strategy on diet, physical activity and health. Geneva: WHO; 2004.

15. Biospace. InBody 720 - The precision body composition analyzer (user's manual). 2008.

16. Schneider PL, Crouter S, Bassett DR. Pedometer measures of free-living physical activity: comparison of 13 models. Med Sci Sports Exerc. 2004;36(2):331-5.

17. Tudor-Locke CE, Myers AM. Methodological considerations for researchers and practitioners using pedometers to measure physical (ambulatory) activity. Res Q Exerc Sport. 2001;72(1):1-12

18. Andersen RE. Obesity: etiology, assessment, treatment and prevention. Champaign, IL: Human Kinetics; 2003.

19. Fox KR. Self-esteem, self-perceptions and exercise. Int J Sport Psychol. 2000;31(2):228-40.

20. O’Meara S, Glenny AM, Sheldon T, Melville A, Wilson C. Systematic review of the effectiveness of inter-ventions used in the management of obesity. J Hum Nutr Diet. 1998;11(3):203-6.

21. Seidell JC, Bouchard C. Visceral fat in relation to health: is it a major culprit or simply an innocent bystander? Int J Obes Relat Metab Disord. 1997;21(8):626-31.

22. Sofková T, Přidalová M. Somatic characteristics in relation to meeting recommended physical activity in overweight and obese women aged 30-60 years. Acta Gymn. 2015;45(3):121-8.

23. Hawkins SA, Wiswell RA. Rate and mechanism of maximal oxygen consumption decline with aging: implications for exercise testing. Sports Med. 2003;33(12):877-88.

24. Hughes VA, Frontera WR, Roubenoff R, Evans WJ, Singh MA. Longitudinal changes in body composition in older men and women: role of body weight change and physical activity. Am J Clin Nutr. 2002;76(2):473-81.

25. Kalvach Z, Zadák Z, Jirák R, Zavázalová H, Holmerová I, Weber P, et al. Geriatric syndromes and geriatric patients. Prague: Grada; 2008. (In Czech.)

26. King NA, Hopkins M, Caudwell P, Stubbs RJ, Blundell JE. Beneficial effects of exercise: shifting the focus from body weight to other markers of health. Br J Sports Med. 2009;43(12):924-7.

27. Ross R, Janiszewski PM. Is weight loss the optimal target for obesityrelated cardiovascular disease risk reduction? Can J Cardiol. 2008;24 Suppl D:25D-31D

28. Annesi JJ. Relationship of perceived health and appearance improvement and self-motivation with adherence to exercise in previously sedentary women. Eur J Sport Sci. 2004;4(2). doi: 10.1080/17461390400074203.

29. Racette SB, Deusinger SS, Deusinger RH. Obesity: overview of prevalence, etiology, and treatment. Phys Ther. 2003;83(3):276-88.

30. Bravata DM, Smith-Spangler C, Sundaram V, Gienger AL, Lin N, Lewis $\mathrm{R}$, et al. Using pedometers to increase physical activity and improve health: a systematic review. JAMA. 2007;298(19):2296-304.

31. Lubans DR, Morgan PJ, Tudor-Locke C. A systematic review of studies using pedometers to promote physical activity among youth. Prev Med. 2009;48(4):307-15.

32. Kang M, Marshall SJ, Barreira TV, Lee J. Effect of pedometer-based physical activity interventions: a meta-analysis. Res Q Exerc Sport. 2009;80(3):648-55.

33. Sofková T, Přidalová M, Mitáš J, Pelclová J. The level of neighborhood walkability in a place of residence and its effect on body composition in obese and overweight women. Cent Eur J Public Health. 2013 Dec;21(4):184-9. 